\title{
Estudio de una tecnología de extracción y fraccionamiento de aceite de ñandú de alta calidad para su utilización en la industria cosmética y farmacéutica
}

\author{
Márquez, R. ${ }^{(1)}$, Repiso, L. ${ }^{(1)}$, Sala, A. ${ }^{(1)}$, Sallé, L. ${ }^{(1)}$, Silvera, C. ${ }^{(2)}$ \\ Contacto: rmarquez@latu.org.uy \\ (1) Gerencia de Proyectos Alimentarios -Laboratorio Tecnológico del Uruguay (LATU) - ${ }^{(2)}$ Facultad de Ingeniería - \\ Universidad Católica del Uruguay (UCUDAL)
}

\begin{abstract}
Resumen
El propósito de este estudio fue aplicar la metodología de extracción con calor en condiciones de vacío a grasa cavitaria y exterior para la obtención de aceite de ñandú (Rhea americana) con condiciones, una vez refinado, de humedad, acidez, índice de peróxidos, color y perfil de ácidos grasos compatibles con las exigencias del comercio internacional para los aceites de ratites. En cuanto al método de refinación seleccionado fue el método de refinación alcalina. Las condiciones elegidas para la neutralización fueron: $\mathrm{NaOH} 10 \%$ y $0.1 \%$ de exceso de la misma. Luego el aceite se lava hasta un contenido de jabones inferior a $50 \mathrm{ppm}$ debido a que los mismos afectan el valor de acidez. De esta forma se lograron valores de acidez muy por debajo del límite requerido por la AEA (American Emu Association) para el aceite de emú extra refinado. Se utilizó tierra de blanqueo Supreme 126 (marca Tonsil de Quimica Sumex S.A.), en una concentración del $0.5 \%$. Se determinó que no existen diferencias sustanciales entre la grasa cavitaria y exterior y en el proceso de winterización se obtienen dos fracciones con perfil de ácidos grasos diferentes siendo la oleína más rica en ácidos grasos insaturados. El contenido de oleico prácticamente no varía entre las fracciones, mientras que el porcentaje de linoleico (ácido graso esencial) es superior para la oleína. En el presente trabajo se obtuvo un aceite cuyas características y parámetros de calidad son aceptables para los requerimientos internacionales que deben poseer los aceites para aplicación en cosmética, haciéndolo factible de comercializar. Por tanto los métodos de extracción y refinación adaptados para esta aplicación son adecuados y simples de aplicar.

Palabras clave: Aceite de ñandú, Rhea americana, ratites, aplicaciones cosméticas, aplicaciones farmacéuticas, grasa cavitaria, grasa exterior.

Abstract

This study was made to apply the extraction method with temperature and vaccum application to internal and external fat of nandú (Rhea Americana) to obtain a ñandú oil which once refined, has the humidity, acidity, peroxide value, color and fatty acid content similar to the ones required for the international trade of ratities oil. The refine method was the alkali one. The conditions used for the neutralization were $\mathrm{NaOH} 10 \%$ with $0.1 \%$ in excess. Then the oil was washed until a soap content lower than 50 ppm because they affect the acidity value. In this way the acidity values obtained were lower than the ones required from the AEA (American Emu Association) for the emu extra refined oil. Supreme 126 earth was used for the whitewash in a concentration of $0.5 \%$. There was found no differences between the internal and the external fat. In the winterization process there were obtained two fractions with different fatty acid contain: the olein fraction was richer in unsaturated fatty acids. The oleic acid content was almost the same in both fractions, while the linoleic acid was higher for the olein fraction. In this study the product was an oil which characteristics and quality parameters are acceptable for the international requeriments for the oils used in cosmetics, and make it easy to trade. Because of this the extraction and refination methods applied are suitable for this use.
\end{abstract}

Key words: ñandú oil, Rhea Americana, ratities, cosmetic applications, pharmaceutical applications, internal fat, external fat.

\section{Introducción}

El ñandú o rhea americana es un ave autóctona de Sudamérica, principalmente la región patagónica argentina y Uruguay, utilizada por los habitantes de estas tierras desde antes de la colonización. Uruguay es el mayor criador de esta ave en el mundo. La comercialización y producción del ñandú se basa en 3 productos fundamentales: la carne, el cuero y la grasa. En el presente estudio nos restringiremos al estudio de la grasa y a la extracción del aceite para uso comercial.

A nivel mundial el aceite de ratites más conocido es el de emú. Esta ave es de la misma familia del ñandú y tiene mayor cantidad de grasa bajo la piel. La grasa en estos animales se localiza sobre todo en el abdomen. Los resultados de diversas experiencias lo definen como una receta natural para aliviar dolores musculares, reumáticos y heridas, tratar inflamaciones, atenuar cicatrices, curar quemaduras y enfermedades de la piel. Posee propiedades bactericidas y antiinflamatorias, hipoalergénicas y capacidad hidratante. Recientemente fue clasificado como "un producto cosmético y farmacéutico" por el Departamento de Salud de Australia.
Tanto en emú como en ñandú el ácido graso más frecuente es el oleico, seguido del ácido palmítico, y también contienen el linoleico. El aceite de emú está casi en su $100 \%$ formado por triglicéridos lo cual significa es un lípido casi neutro.

Los aceites obtenidos de las tres especies de ratites, a saber el emú, el avestruz y ñandú parecen ser similares en su composición básica. En estos aceites predominan los siguientes ácidos grasos: oleico, palmítico, esteárico y linoleico. Las proporciones de estos ácidos grasos variarán algo según el tipo de ave y posiblemente el tipo de alimentación.

Estos aceites se obtienen por procesos de extracción convencionales si bien los parámetros del proceso tienen que ser modificados para preservar el grado alto de insaturación que poseen.

En este trabajo se pretendió poner a punto un método para la extracción y el refinado del aceite para que alcance los estándares internacionales con el fin de que se pueda comercializar.

Se analizaron los aceites obtenidos a partir de grasa cavitaria y grasa exterior para determinar si ambas son aptas para su comercialización y se determinaron sus perfiles de ácidos grasos. 


\section{Materiales y Métodos}

1) Caracterización de materia prima

La grasa utilizada fue de una faena reciente, con menos de 30 días de faenada y conservada al vacío a $-18^{\circ} \mathrm{C}$.

Con el objetivo de conocer la composición de la materia prima se realizaron los análisis de humedad, materia grasa y cenizas. Los métodos utilizados fueron los métodos recomendados por AOAC para aceites comestibles (humedad: método AOCS Ca 2d-25, materia grasa: método AOAC 985.15, y cenizas: método AOAC 923.03). Los ensayos se hicieron por triplicado.

A su vez se realizaron los análisis de peróxidos (Método AOCS cd 8-53) y acidez (Método AOCS ca 5a-40) con el objetivo de determinar el grado de deterioro de la grasa.

2) Método de extracción

Se procesó la grasa en una procesadora doméstica para romper las estructuras celulares, y homogenizar la muestra. Luego se calentó la misma en un baño de agua a $100{ }^{\circ} \mathrm{C}$ para mantener constante la temperatura de la pared del recipiente y se realizó el tratamiento hasta que la temperatura del aceite alcanzó los $70^{\circ} \mathrm{C}$. El proceso se realizó con agitación y con el recipiente a vacío. Luego se procedió a filtrar el aceite en caliente en primer lugar con un filtro de acero inoxidable de malla de $3 \mathrm{~mm}$ y luego con papel de filtro Wathman 41 para eliminar los restos de sólidos presentes.

3) Diferenciación de grasa cavitaria y exterior

Con el objetivo de determinar si existen diferencias entre la grasa cavitaria y exterior se realizaron los ensayos: índice de peróxidos, acidez, humedad y perfil de ácidos grasos (AOCS Ce2-66), a las muestras procesadas según se indicó en el punto anterior, en forma separada. Todos los ensayos se realizaron por duplicado.

4) Caracterización del aceite crudo obtenido

El aceite obtenido se caracterizó mediante los ensayos: índice de peróxidos, acidez, humedad y perfil de ácidos grasos, con la metodología ya indicada.

5) Método de refinación

Con el objetivo de obtener el aceite refinado se ensayaron diferentes condiciones para esta etapa, de manera de obtener un aceite que cumpliera con las especificaciones requeridas por la American Emu Association (AEA) para el aceite de emú completamente refinado. Se utilizó el método de refinación alcalina, neutralizando los ácidos grasos libres con $\mathrm{NaOH}$ al $10 \%$ con un $0.1 \%$ de exceso. Luego se dejó decantar por una hora a 60 ${ }^{\circ} \mathrm{C}$ y se lavó con salmuera al $3 \%$ hasta obtener jabones menores a 50 ppm. Para el blanqueo se utilizó una arcilla activada Supreme 126 (marca Tonsil de Química Sumex S.A.), en una concentración del $0.5 \%$ y se calentó a vacío durante 45 minutos a $90^{\circ} \mathrm{C}$.

6) Caracterización del aceite refinado

$\mathrm{Al}$ aceite refinado obtenido se le determinó el perfil de ácidos grasos por cromatografía gaseosa.

Por otro lado, al aceite refinado también se le realiza el proceso de winterizado. Para ello se enfría a $10{ }^{\circ} \mathrm{C}$ durante 6 horas y se filtra en papel de Whatman 41 resultando de ello dos fracciones: liquida (oleica) y sólida (esteárica), a las cuales también se les determina el perfil de ácidos grasos.

\section{Resultados}

En el Cuadro 1 se puede observar que la materia prima está compuesta mayoritariamente por compuestos lipídicos y que luego de la extracción se eliminan los demás componentes quedando sólo la humedad.

\begin{tabular}{|c|c|c|c|}
\hline & humedad $(\boldsymbol{\%})$ & materia grasa $(\boldsymbol{\%})$ & cenizas $(\boldsymbol{\%})$ \\
\hline grasa & 8,30 & 80,23 & 0,007 \\
\hline aceite & 0,21 & 99,79 & 0 \\
\hline
\end{tabular}

Cuadro 1 Comparación de parámetros principales en grasa y aceite

\begin{tabular}{|c|c|}
\hline $\begin{array}{c}\text { Índice de peróxidos } \\
\text { (m.e.q O2 / Kg.) }\end{array}$ & $\begin{array}{c}\text { acidez (\%) } \\
\text { expresado como ác. oleico }\end{array}$ \\
\hline 2.83 & 0.38 \\
\hline
\end{tabular}

Cuadro 2 Determinaciones realizadas al aceite extraído

\begin{tabular}{|c|c|c|c|}
\hline Análisis & $\begin{array}{c}\text { Aceite } \\
\text { crudo }\end{array}$ & $\begin{array}{c}\text { Aceite } \\
\text { refinado }\end{array}$ & $\begin{array}{c}\text { Aceite } \\
\text { refinado } \\
\text { completamente }\end{array}$ \\
\hline $\begin{array}{c}\text { Índice de } \\
\text { peróxidos } \\
\text { (meq } \\
\text { peróxidos / Kg) }\end{array}$ & $\begin{array}{c}\text { No se tiene } \\
\text { referencia }\end{array}$ & $\begin{array}{c}\text { No se tiene } \\
\text { referencia }\end{array}$ & 2 \\
\hline Acidez (\%) & 0.75 & 0.10 & 0.10 \\
\hline Humedad(\%) & 0.5 & 0.10 & 0.05 \\
\hline $\begin{array}{c}\text { Color } \\
\text { Lovinbond } \\
51 / 4 ”\end{array}$ & 4 rojo & 1.5 rojo & 8 amarillo/ \\
0.8 rojo
\end{tabular}

Cuadro 3 Parámetros de calidad para aceite de emú según AEA

En el Cuadro 2 se exponen los valores de índice de peróxidos y acidez obtenidos en las muestras de aceite extraído. Se observa que el valor de acidez es inferior a límite establecido por AEA para aceite crudo que es de $0.75 \%$, y el índice de peróxidos es apenas superior al valor establecido para el aceite completamente refinado.

\begin{tabular}{|c|c|c|c|}
\hline $\begin{array}{c}\text { Origen del } \\
\text { aceite }\end{array}$ & $\begin{array}{c}\text { humedad } \\
(\%)\end{array}$ & $\begin{array}{c}\text { acidez } \mathbf{( \% )} \\
\text { expresado } \\
\text { como ác. oleico }\end{array}$ & $\begin{array}{c}\text { Índice de } \\
\text { peróxidos } \\
\text { (meq O2 / Kg.) }\end{array}$ \\
\hline $\begin{array}{c}\text { Grasa } \\
\text { cavitaria }\end{array}$ & 0.10 & 0,27 & 1,10 \\
\hline $\begin{array}{c}\text { Grasa } \\
\text { exterior }\end{array}$ & 0,03 & 0,17 & 0,94 \\
\hline
\end{tabular}

Cuadro 4 Diferenciación entre grasa cavitaria y exterior

\begin{tabular}{|c|c|c|c|c|}
\hline & \multicolumn{2}{|c|}{ Grasa cavitaria } & \multicolumn{2}{c|}{ Grasa exterior } \\
\hline componente & grasa & aceite & grasa & aceite \\
\hline C14:0 & 0 & 0,5 & 0,1 & 0,1 \\
\hline C1.6:0 & 33,7 & 25,9 & 28,4 & 23,5 \\
\hline C16: 1 cis & 0,8 & 2,3 & 1,4 & 4,2 \\
\hline C18:0 & 3,5 & 7,1 & 1,9 & 8,1 \\
\hline C18:1 cis & 39,3 & 36,7 & 39,5 & 33,9 \\
\hline C18:1 trans & & & & 0,2 \\
\hline C18:2 cis & 21,9 & 25,2 & 26,4 & 24,3 \\
\hline C18:3 trans & & & & \\
\hline C18:3 cis & 0,7 & 2 & 2,3 & 3,5 \\
\hline & 99,9 & 99,9 & 100 & 99,7 \\
\hline
\end{tabular}

\begin{tabular}{|c|c|c|c|c|}
\hline & \multicolumn{2}{|c|}{ Grasa cavitaria } & \multicolumn{2}{c|}{ Grasa exterior } \\
\hline & grasa & aceite & grasa & aceite \\
\hline $\begin{array}{c}\text { Ácidos grasos } \\
\text { saturados }\end{array}$ & 37,2 & 33,5 & 30,4 & 32,7 \\
\hline $\begin{array}{c}\text { Ácidos grasos } \\
\text { monoinsaturados }\end{array}$ & 40,1 & 39 & 40,9 & 38,5 \\
\hline
\end{tabular}




\begin{tabular}{|c|c|c|c|c|}
\hline $\begin{array}{c}\text { Ácidos grasos } \\
\text { poliinsaturados }\end{array}$ & 22,6 & 27,4 & 28,7 & 28,5 \\
\hline $\begin{array}{c}\text { Ácidos grasos } \\
\text { insaturados }\end{array}$ & 62,7 & 66,4 & 69,6 & 67 \\
\hline & 99,9 & 99,9 & 100 & 99,7 \\
\hline
\end{tabular}

Cuadro 5 Perfil de ácidos grasos en la grasa y el aceite proveniente de grasa cavitaria y exterior.

A partir de los cuadros 4 y 5 se puede observar que no existen diferencias sustanciales entre la grasa cavitaria y exterior tanto desde el punto de vista del perfil de ácidos grasos como de los demás parámetros de calidad. El aceite obtenido cumple con las especificaciones para el aceite crudo de emú y su perfil de ácidos grasos muestra que es un aceite rico en ácidos grasos poliinsaturados.

El perfil de ácidos grasos obtenido para el aceite refinado es el que se muestra en el Cuadro

6. Se puede apreciar que durante el proceso de refinación del aceite se produce un deterioro del mismo, ya que disminuye la cantidad de ácidos grasos poliinsaturados y aumenta el correspondiente ácido graso insaturado y saturado. A su vez se observa la diferencia entre ambas fracciones viendo que la estearina (fracción sólida) tiene una cantidad de ácidos grasos mayor que la oleína (fracción liquida). Mientras que la oleína es rica en oleico, la estearina es rica en palmítico. El diagrama de obtención de ambas fracciones se observa en la Figura 1.

\begin{tabular}{|c|c|c|c|c|c|}
\hline & & $\begin{array}{c}\text { Aceite } \\
\text { crudo }\end{array}$ & $\begin{array}{c}\text { Aceite } \\
\text { refinado }\end{array}$ & Estearina & Oleína \\
\hline 14:0 & Mirístico & 0.6 & 0.5 & ------- & 0.2 \\
\hline 16:0 & Palmítico & 25.6 & 31.6 & 42.2 & 27.1 \\
\hline 16:1 & Palmitoleico & 3.8 & 2.2 & 1.4 & 1.1 \\
\hline 18:0 & Esteárico & 8.1 & 5.5 & 3.8 & 2.2 \\
\hline 18:1 & Oleico & 38.6 & 43.0 & 42.3 & 49.9 \\
\hline 18:2 & Linoleico & 20.6 & 16.5 & 10.4 & 19.0 \\
\hline 18:3 & Linolénico & 1.5 & 0.7 & -------- & 0.5 \\
\hline 20:0 & Aráquico & 0.1 & -------- & --------- & ------- \\
\hline
\end{tabular}

Cuadro 6 Perfil de ácidos grasos del aceite crudo y refinado, y de las fracciones esteárica y oleica

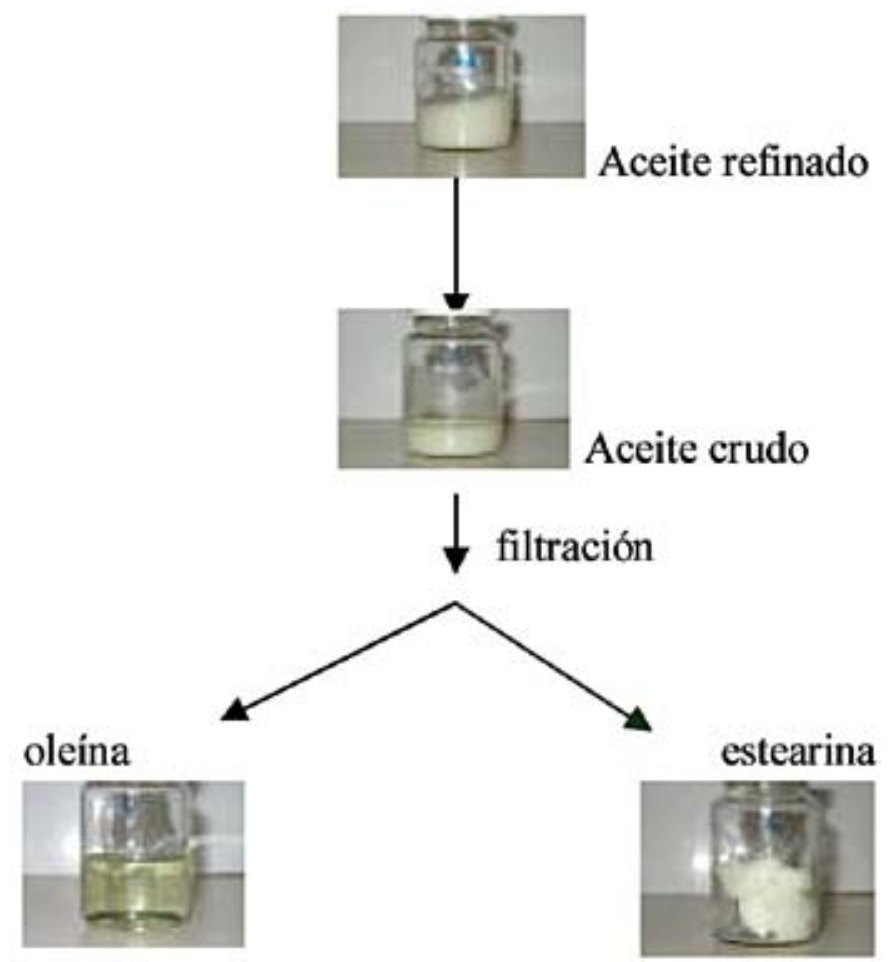

Figura 1 Diagrama de obtención de la oleína y la estearina

\begin{tabular}{|c|c|}
\hline Parámetro determinado & Aceite refinado \\
\hline Índice de peróxidos(meq perox / Kg) & 0,4 \\
\hline Humedad (\%) & Menor a 0.05 \\
\hline Acidez libre (\%) & 0.06 \\
\hline Color Lovibond & 5.0 Amarillo -1.1Rojo \\
\hline
\end{tabular}

\section{Cuadro 7 Análisis de aceite refinado}

En el cuadro 7 podemos ver que el aceite cumple con los requerimientos para el aceite completamente refinado.

\section{Conclusiones}

En el presente trabajo se obtuvo un aceite cuyas características y parámetros de calidad son aceptables para los requerimientos internacionales que deben poseer los aceites para aplicación en cosmética, haciéndolo factible de comercializar. Puede afirmarse por tanto que los métodos de extracción y refinación adaptados para esta aplicación son adecuados y simples de utilizar. A su vez se determinó que no existen diferencias sustanciales en los parámetros medidos (índice de peróxidos, acidez, humedad, perfil de ácidos grasos insaturados) entre la grasa cavitaria y exterior. Esto indica que se pueden utilizar indistintamente los dos tipos de grasa del ñandú, mientras que en el caso del emú sólo se utiliza una de ellas. En el proceso de winterización se obtienen dos fracciones con perfil de ácidos grasos diferentes siendo la oleína más rica en ácidos grasos insaturados. El contenido oleico prácticamente no varía entre las fracciones, mientras que el porcentaje de linoleico (ácido graso esencial) es superior para la oleína. Cabe destacar que para este proceso de refinación no se pudo realizar como es debido una desodorización por no contar con el equipamiento adecuado lo que mejoraría aún más los valores de peróxidos. Para este paso se está ensayando el proceso de destilación molecular, el cual es utilizado en Estados Unidos para refinar aceite de emú.

\section{Reconocimientos}

CLE (Consorcio Latinoamericano de Exportación) Centro de Información del LATU Departamento de Cereales, Oleaginosos y Productos Derivados del LATU Departamento de Cromatografía y Espectrometría de Masa de Alimentos del LATU

\section{Referencias}

Costa, E. 2003. Permeabilidad cutánea : aspectos biofarmacéuticos. En: Revista Asociación de Química y Farmacia del Uruguay. (38):13-16

Craig-Schmidt, M. 1997. Emú premier oil bird. En: Inform. 8(3): 246-252

Dhal, Olle. Industrialización de la grasa de animales de abasto. Zaragoza : Acribia, 1976.

FAO ; OMS. Grasas y aceites en la nutrición humana. Consulta FAO/OMS de expertos. Roma : OMS, 1997. (Estudio FAO Alimentación y Nutrición -(57). Disponible en: http://www.fao.org/docrep/v4700s/v4700s00.htm

Grompone, M. 2005. Uruguayan ñandú oil : a comparation with emú and ostrich oils. En: JAOCS. 82(9):687-689.

Hernández, E. Emu oil Processing and Properties. Texas: Food Protein R \& D Center Texas A \& M University. Disponible en:http://lbemuoil.com/processing emu_oil.htm

Hernández, E. Processing of ratite oils. Texas : Food Protein R \& D Center Texas A \& M University. Disponible en: http://www.portaluruguay.net/modules.php?op $=$ modload $\&$ name $=$ News $\&$ file $=$ article $\&$ sid $=1197$

Méndez, E. et all. 1998. Fatty acid composition extraction fractionation and stabilization of bullfrog (Rana catesbeiana) oil. En: JAOCS. 75(1): 67-71.

Process for the extraction of lipids from fatty bird tissues. United States Patent Application Publication No 2002/0133033

Processing of ratites oils. Disponible en: http://www.highcascadeemus.com/ article6.html Swern, D. Bailey's Industrial Oil \& Fat Products. John Wiley \& Sons.

1996 Thompson, P. 2002. Tjuringa Emu Products. Second Draft. Research and documentation colattionemú products. Maleny, Australia.

Uruguay. Ministerio de Salud Pública. Reglamento Bromatológico Nacional, Decreto 315/1994. Montevideo : IMPO. 2005 